\title{
AUTOMATED LICENSURE EXAMINATION REVIEWER FOR TEACHERS (A.L.E.R.T.): AN INNOVATIVE INTERVENTION REVIEW SYSTEM FOR LSPU CTE STUDENTS
}

\author{
Christian P. San Luis \\ ian.sanluis@1spu.edu.ph \\ Laguna State Polytechnic University, Sta. Cruz, Laguna 4009 PHILIPPINES
}

\begin{abstract}
One of the measures of quality education provided by Higher Education Institutions (HEIs), especially those offering board programs, is the performance of their graduates in the licensure examinations being conducted by the Professional Regulation Commission (PRC). A graduate must prepare and may use different review interventions such as attending review classes aside from other personal preparations, to increase chances of passing the licensure examination.
\end{abstract}

On this premise, the proponent had developed a new review platform the Automated Licensure Examination Reviewer for Teachers (A.L.E.R.T.) to be utilized by the students of Laguna State Polytechnic University under the College of Teacher Education which can help improve CTE students in acquiring skills needed in passing the licensure examination for teachers. It focuses on the idea that this reviewer is a PC-based (stand-alone) application that can generate sets of review materials mainly on General and Professional Education subjects which the learners can answer using computers.

Furthermore, the developed reviewer system is to test the system's level assessment in terms of its components such as content, format, graphics, and objectives. The acceptability of its functional characteristics was also assessed in terms of its accessibility, consistency, suitability, and usability. The researcher also aimed to test the level of assessment of the developed system in terms of its overall acceptability, and the significant difference between the levels of assessment of the respondent's rating on its components and characteristics.

The descriptive measure of the respondents specifically the interval data was used in this study. The system was validated by eighty (80) college students and fifteen (15) teachers/instructors from the College of Teacher Education Santa Cruz Main Campus. The level of assessment was determined using the mean value and its standard deviation.

Keywords: Licensure Examination for Teachers; automated; stand-alone application; accessibility; consistency; suitability; usability

\section{INTRODUCTION}

Passing the Licensure Examination for Teachers (LET) is an indicator of quality of education in the implementation of the curriculum given by Higher Educational Institutions (HEIs) down to education 
institutions such as the Laguna State Polytechnic University particularly the College of Teacher Education. It has always been a challenge to increase the institutions' passing rate in terms of the number of passers and to reach the National Passing Percentage for both elementary and secondary education level.

During the September 2018 Licensure Examination for Teachers, the Laguna State Polytechnic University - Sta. Cruz Campus gained an overall performance rate of $33.33 \%$ for the elementary level while $43.07 \%$ for the secondary level. A remarkable increase in the performance rating was attained compared to the rating from the March 2018 licensure examination and the licensure examination conducted in year 2014 to 2017. Although the result of the examination still presents a shortfall of $5.04 \%$ compared to the September 2018 National Passing Rate of $48.03 \%$ for the secondary level.

The College of Teacher Education has targeted twenty-five (25\%) higher than the National Passing Rate of the students taking up Licensure Examination for Teachers every year. Unfortunately, it is saddening to note the fluctuating results of the licensure examination passing rate of the students of Laguna State Polytechnic University Santa Cruz Main Campus as shown in the five (5) year comparison of licensure examination passing rate covering the year 2014 to 2018 for both elementary and secondary level which is presented in Figure 1 and Figure 2.

Figure 1 depicts the performance of LSPU in the Licensure Examination for Teachers for Elementary Level for the year 2014 to 2018.

Figure 1. LSPU Examination LET Performance Rating: Elementary Level

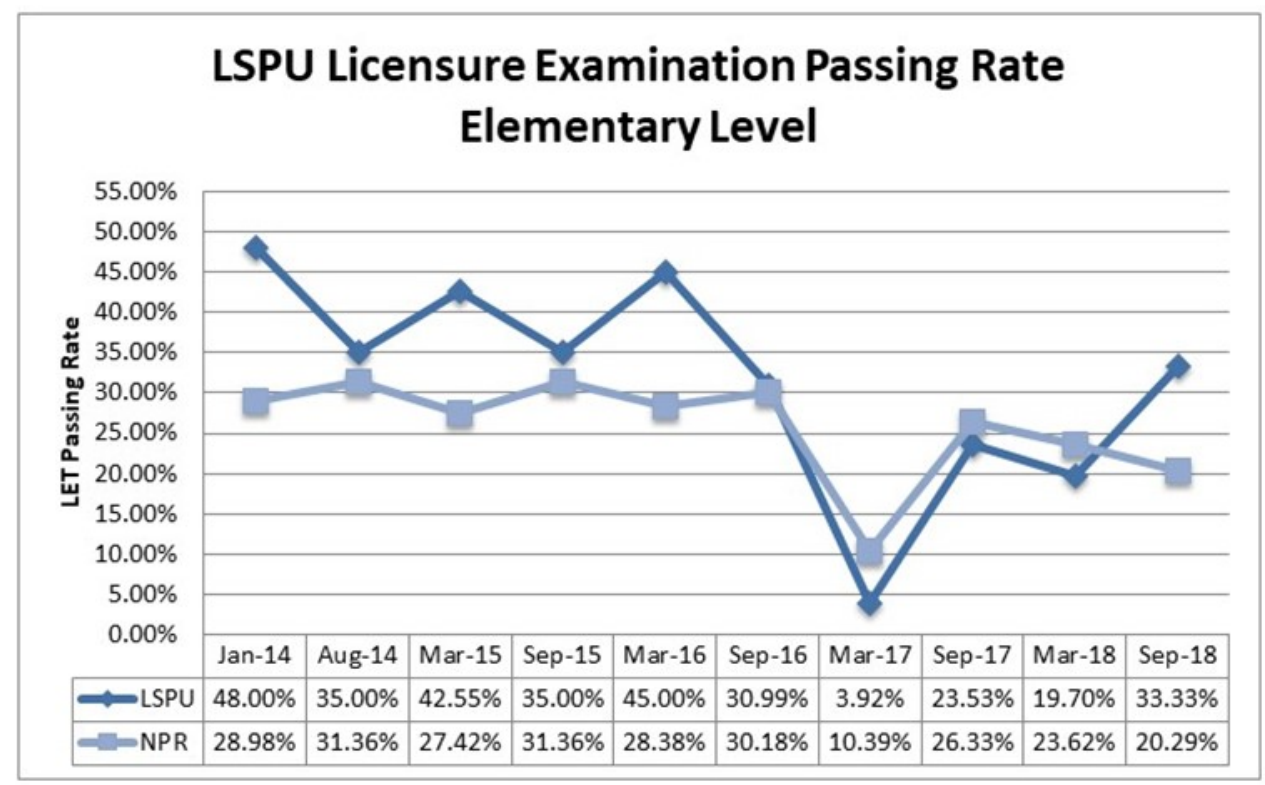

Figure 2 shows the performance rating of LSPU Licensure Examination for Teachers for Secondary Level for the year 2014 to 2018. 
Figure 2. LSPU Examination LET Performance Rating: Secondary Level

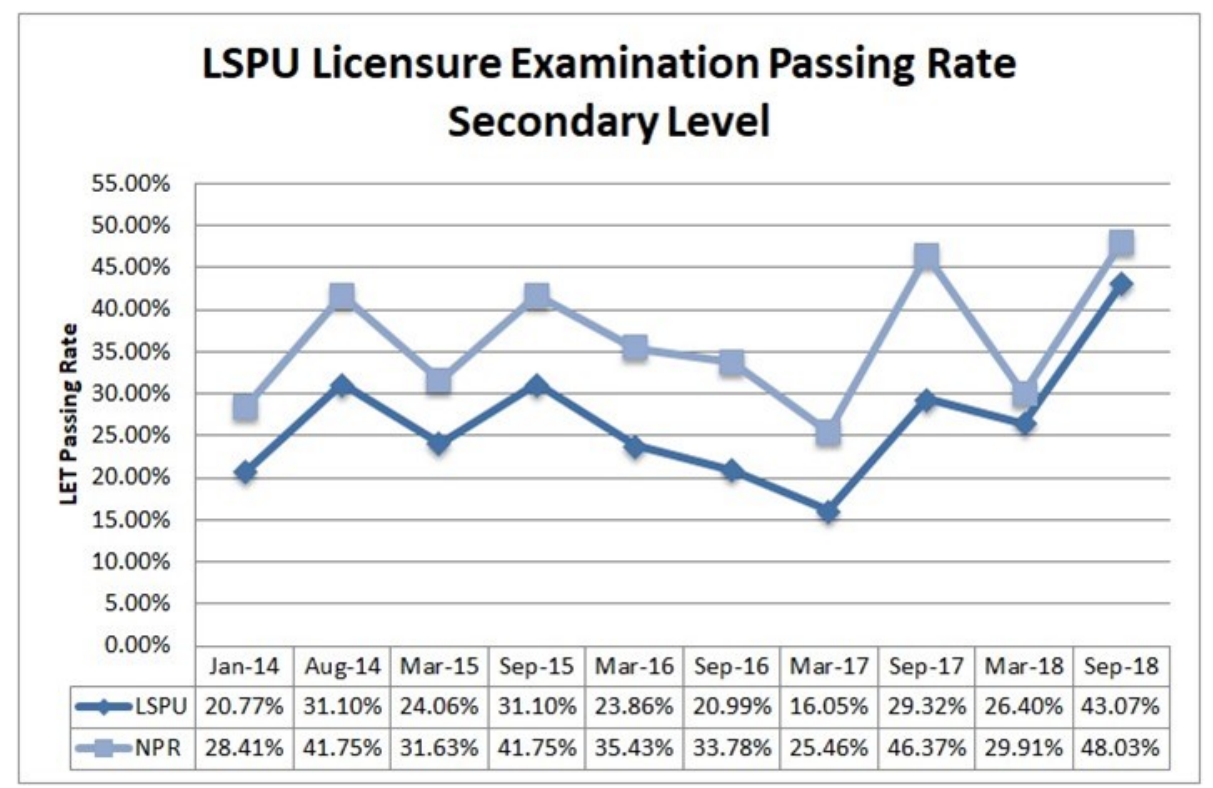

In view of increasing the performance in the LET examination and in response to the call for academic excellence, possible interventions were suggested to enhance program strategies and increase LET performance rating. In this premise, the researcher came up with the idea of introducing an innovative intervention review system which will help students in acquiring skills in preparation for taking the licensure examination for teachers using technology.

Apparently, technology plays a vital role in the field of education in delivering lessons and even in acquiring new learning. Integration of technology in education has been deemed effective in addressing the needs of the students, thus enhances the cognitive abilities of both students and teachers. Much more in computer-based reviewer presents a great advantage compared to traditional paper-based examination reviewer such as efficiency, test question preparation, immediate scoring and feedback.

Similarly, computer-based reviewer allows more innovative and authentic assessment due to the availability of technological advancements for utilization. Hence, the use of computer-based reviewer also has its own disadvantages in terms of additional need for adequate facilities, security issues, backup procedures in case of system failure, and time for the users to be acquainted with the new technology.

With the rationale stated above, the proponent developed an Automated Licensure Examination Reviewer for Teachers (A.L.E.R.T.) application to be utilized by the students of Laguna State Polytechnic University under the College of Teacher Education particularly those preparing for the Licensure Examination for Teachers.

Finally, the study would also determine its acceptability to the respondents in terms of its accessibility, consistency, suitability and usability. 


\subsection{Objective of the Study}

This study aims to develop a new review platform and determine the Automated Licensure Examination Reviewer for Teachers (A.L.E.R.T.) of its components, characteristics as well as its overall acceptability that may help the university's College of Teacher Education students meet the passing percentage in the licensure examination for teachers.

Primarily, this study sought answers to the following:

1. Determine the mean level of assessment of the Automated Licensure Examination Reviewer for Teachers (A.L.E.R.T.) in terms of its components such as:

1.1. content;

1.2. format;

1.3. graphics; and

1.4. objectives.

2. Determine the mean level of assessment of the Automated Licensure Examination Reviewer for Teachers (A.L.E.R.T.) in terms of its characteristics such as:

2.1. accessibility;

2.2. consistency;

2.3. suitability; and

2.4. usability.

3. Determine the level of assessment of the developed Automated Licensure Examination Reviewer for Teachers (A.L.E.R.T.) in terms of its overall acceptability.

4. Determine the significant difference between the levels of assessment of the respondent's rating on the components and characteristics of the Automated Licensure Examination Reviewer for Teachers (A.L.E.R.T.).

\section{LITERATURE}

The Automated Licensure Examination Reviewer for Teachers (A.L.E.R.T) was developed primarily to serve as an aid to meet the needs of the learners to prepare themselves in acquiring the necessary skills and techniques in passing the licensure examination for teachers. Maximizing the use of technology along with the availability of up-to-date and relevant materials may have the greater chance of passing the said examination.

The use of computers, mobile devices, and the Internet is at an all-time high and is expected to rise further as technology becomes more affordable, particularly for users in developing countries (Poushter, 2016). Greater access to and demand for technology has created new opportunities and challenges for many industries, some of which have thrived by effectively digitizing their operations and services (e.g., finance, media), while others have struggled to keep up with the pace of technological innovation (e.g., education, healthcare) (Gandhi, Khanna, and Ramaswamy, 2016).

Accessibility refers to the accessibility of a computer system to all people, regardless of disability type or severity of impairment. It is most often used in reference to specialized hardware or software, or a 
combination of both, designed to enable use of a computer by a person. It means that technology can be utilized anytime and in the comfort of the learner's home by using a computer system.

Accessibility can be linked also to student's engagement to technology. Student's engagement may be defined in two ways: (1) student engagement refers to as a desired outcome reflective of a student's thoughts, feelings, and behaviors about learning. It focuses primarily on student behavior, suggesting that engagement is the "extent to which students are engaging in activities that higher education research has shown to be linked with high-quality learning outcomes" (Coates, 2008) or the "quality of effort and involvement in productive learning activities" (Kuh, 2009). (2) Student engagement refers to as a process involving both the student and the university. For example, Trowler (2010) defined student engagement as "the interaction between the time, effort and other relevant resources invested by both students and their institutions intended to optimize the student experience and enhance the learning outcomes and development of students and the performance, and reputation of the institution".

According to Kamalrudin (2015), software requirement specifications elaborate the functional and non-functional requirements, design artifacts, processes and other aspects of a software system. Software requirement specifications that are complete and accepted by developers and clients provide a shared understanding and agreement of what a software system should do and why. Since requirement documents form the basis of development processes and this agreement, they should be correct, complete, and unambiguous and need to be validated with respect to Consistency, Completeness and Correctness ("3 Cs") to detect errors such as inconsistency and incompleteness (Zowghi and Gervasi, 2003).

In fact, the importance of ensuring consistency, completeness and correctness in the requirements validation process must be properly observed and conducted in the software development cycle. The validation process also helps to determine that the end product is correct and complete as well as to guarantee that the system developed satisfies the stakeholders' original requirements (Bahill and Henderson, 2005).

According to Rodriquez, M. et. al. (2016), functional suitability checks if the product or system provides functions that meet all the stated or implicit needs when used under specific conditions. According to the systematic review carried out in Rodriguez and Piattini (2012), functional suitability is one of the most relevant characteristics, and it is among those that generate the greatest interest. This is because having an evaluation available that indicates the level of fulfilment of the product's functional requirements helps ensure that the software product is suitable for the functions it must perform.

Software functionality service quality reflects how well it complies with or conforms to a given design, based on functional requirements or specification. It can also be described as the fitness for purpose of a piece of software or how it compares to competitors in the marketplace as a worthwhile product (Miguel, Mauricio, and Rodríguez, 2014).

Nowadays, the demand of quality software is increasingly rapidly thus specialized software are commonly used in every institution including HEIs. Yet, there is a wide range of rejections of software systems despite of the huge amount spent in the development of the software. This could be rooted to the non-interaction of the developed software and the failure of the software to fulfil their specific tasks. Usability is vital in every software development and has great influence in the acceptance and rejection of any developed software. Usability is defined as 'the ease with which a user can learn to operate, prepare inputs for, and interpret outputs of a system or component' (IEEE Std.1061, 1992 as cited by Madan, A. et al., 2012). 
In addition, Madan, A. et al. (2012) states that usability correlates with the functionality of the system and helps in its evaluation. The lack of usability causes failure of the software system that leads to a substantial monetary loss, user dissatisfaction, staff unproductivity and time wastage. Therefore, usability evaluation is very important for the process of designing usable software system.

Nielsen Model (2012) studied and recognized usability as an important attribute to influence the acceptance of a product. He divided acceptability into practical and social acceptance and further on gave five sub attributes of usability namely learnability, efficiency, memorability, errors, and satisfaction (Madan, A. et al., 2012). Learnability represents how easy for the users to be accomplish basic task the first time they encounter or used the software. Efficiency represents how easy the developed software performs the desired tasks or outcomes. Memorability is the ease to re-establish the use of the software even not using the software for a period of time. Errors signify to the total number of errors committed by the user, its severity and how easily the user recovers from the errors. Satisfaction represents how pleasant it is to us the program. This is coined to as the user-friendliness of the developed software.

Another key attribute of usability is utility. Utility refers to as how the developed system can meet the user's needs or simply refers to the system's functionality. Therefore, any system that has no utility for the user lacks the functions and features required, thus will not be able to help the user achieve their goals (Harrison, R. et al., 2013).

International Standards Organization (ISO) standard 9241-11 gives the meaning of usability as the "extent to which a product can be used by specified users to achieve specified goals with effectiveness, efficiency and satisfaction in a specified context of use" (W. ISO (1998) as cited by Harrison, R. et al., 2013).

\section{METHODOLOGY}

The study was conducted at Laguna State Polytechnic University (LSPU) Santa Cruz Main Campus. The researcher identified two sets of respondents: (1) teachers with at least 2 years teaching experience and preferably licensed professional teachers; and (2) second year college students from the Laguna State Polytechnic University Santa Cruz Campus College of Teacher Education, as they are the target end-users of the proposed review platform. Respondents validated the developed Automated Licensure Examination Reviewer for Teachers (A.L.E.R.T.) in terms of its components such as its content, format, graphics and objectives and its characteristics such as accessibility, consistency, suitability and usability.

Purposive sampling was used in the selection of respondents for the first group of evaluators comprised of teachers as they are experts in technology and in the academe and has the experience of taking up the licensure examination for teachers. Likewise, random sampling was used to select respondents from the group of students. The first group of respondents was composed of fifteen (15) teachers and the second group was composed of eighty (80) college students from the College of Teacher Education.

In order to analyze and interpret the data gathered the following statistical tools used were Weighted Mean and Standard Deviation to determine the mean level of assessment of the Automated Licensure Examination Reviewer for Teachers (A.L.E.R.T.) in terms of its components and characteristics while T-Test was used to determine the significant difference between the levels of assessment of the respondent's rating on the components and characteristics of the Automated Licensure Examination Reviewer for Teachers (A.L.E.R.T.). 
For the development of the material, the researcher was guided by the following stages to serve its purpose:

Figure 3. Stages in Development of the Automated Licensure Examination Reviewer for Teachers (A.L.E.R.T.)

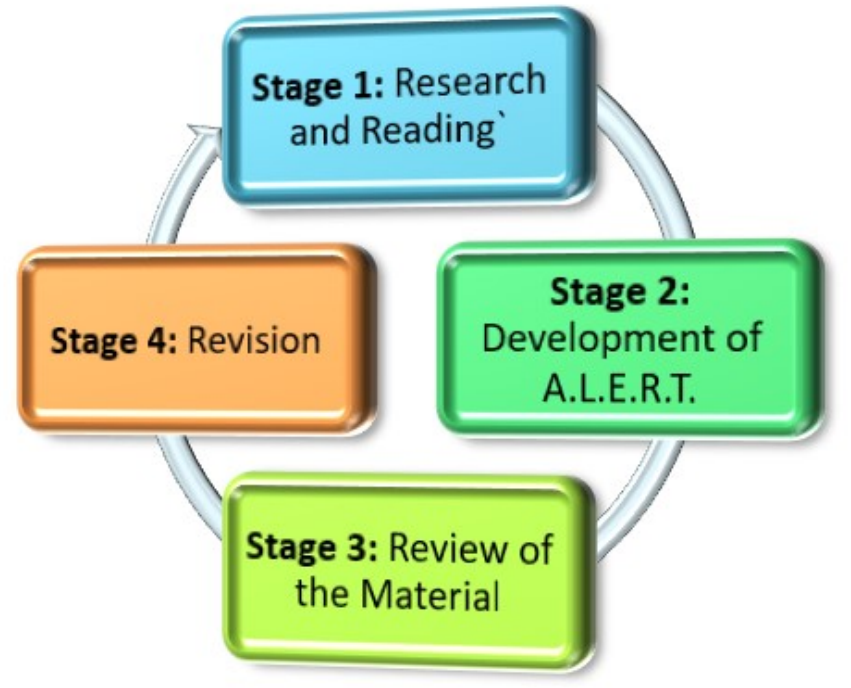

Stage 1. Research and Reading. Substantive ideas were gathered through reading books, researches, thesis and dissertations from different authors, notes, and conducting interviews and consultations to ensure the quality of the material.

Stage 2. Development of the Automated Licensure Examination Reviewer for Teachers (A.L.E.R.T.). The researcher started the development of the material after gathering of relevant information.

Stage 3. Review of the Material. After the development of the reviewer, the material was reviewed by the adviser and experts in relation to the material's design, content and appropriateness and to gain advice for further improvement.

Stage 4. Revision. All solicited suggestions and recommendations from the experts were the basis for the revision for the overall success of the developed material.

The researcher prepared the research instrument in a form of a questionnaire to evaluate the components of the Automated Licensure Examination Reviewer for Teachers (A.L.E.R.T.) in terms of its content, format, graphics and objectives, likewise to generate assessment of its acceptability in terms of its accessibility, consistency, suitability and usability among the respondents.

The questionnaire was divided into three parts:

1. Personal Information of the respondents.

2. Questions to assess its components in terms of content, format, graphics and objectives.

3. Questions to assess its level of acceptability in terms of accessibility, consistency, suitability, and usability. 
In order to avoid guesswork and to obtain one-hundred percent responses, the questionnaire is provided with a five-point likert-type scale of optional answer with equivalent range and verbal interpretation as follows:

$\begin{array}{cc}\text { Scale } & \text { Range } \\ 5 & 4.20-5.00 \\ 4 & 3.40-4.19 \\ 3 & 2.60-3.39 \\ 2 & 1.80-2.59 \\ 1 & 1.00-1.79\end{array}$

In order to analyze and interpret the data gathered the following statistical tools used were Weighted Mean and Standard Deviation to determine the mean level of assessment of the Automated Licensure Examination Reviewer for Teachers (A.L.E.R.T.) in terms of its components and characteristics while T-Test was used to determine the significant difference between the levels of assessment of the respondent's rating on the components and characteristics of the Automated Licensure Examination Reviewer for Teachers (A.L.E.R.T.).

\section{RESULTS AND DISCUSSIONS}

The study was conducted to determine the level of assessment of the developed Automated Licensure Examination Reviewer for Teachers (A.L.E.R.T.) in terms of its components and characteristics. Data have been gathered, tallied, analyzed, tabulated and then processed in response to the stated objectives of the study.

Table 1 shows the overall level of assessment of teachers and students on the components of the Automated Licensure Examination Reviewer for Teachers (A.L.E.R.T).

Table 1. Assessment of Automated Licensure Examination Reviewer for Teachers (A.L.E.R.T.) in terms of its Component

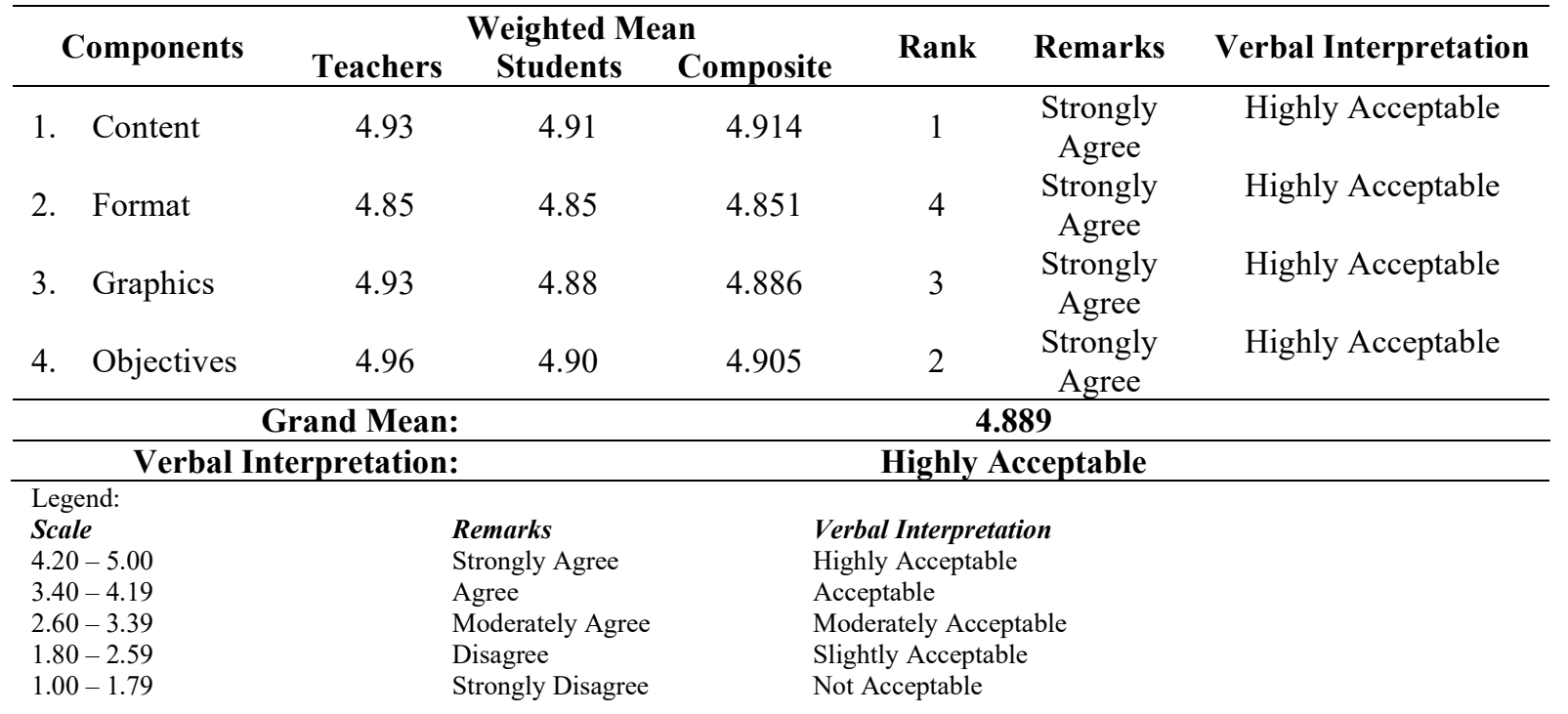


It affirms that the most significant among its components was, the content with (WM=4.914) placing it on the first rank, which depicts the importance of the content and serves as the soul of the system. The item that ranked last is format with (WM=4.851). Assessing it in terms of its component received an overall rating of $(\mathrm{WM}=4.889)$ with a verbal interpretation of "Highly Acceptable."

Table 2 shows the overall level of assessment of teachers and students on the characteristics of the Automated Licensure Examination Reviewer for Teachers (A.L.E.R.T).

Table 2. Overall Assessment Rank of Automated Licensure Examination Reviewer for Teachers (A.L.E.R.T.) in terms of its Characteristics

\begin{tabular}{|c|c|c|c|c|c|c|}
\hline \multirow[b]{2}{*}{ Characteristics } & \multicolumn{3}{|c|}{ Weighted Mean } & \multirow{2}{*}{ Rank } & \multirow[b]{2}{*}{ Remarks } & \multirow[b]{2}{*}{ Verbal Interpretation } \\
\hline & Teachers & Students & Composite & & & \\
\hline 1. Accessibility & 4.93 & 4.89 & 4.897 & 4 & $\begin{array}{c}\text { Strongly } \\
\text { Agree }\end{array}$ & Highly Acceptable \\
\hline 2. Consistency & 4.93 & 4.92 & 4.920 & 2 & $\begin{array}{l}\text { Strongly } \\
\text { Agree }\end{array}$ & Highly Acceptable \\
\hline 3. Suitability & 4.89 & 4.90 & 4.901 & 3 & $\begin{array}{c}\text { Strongly } \\
\text { Agree }\end{array}$ & Highly Acceptable \\
\hline 4. Usability & 4.96 & 4.94 & 4.941 & 1 & $\begin{array}{c}\text { Strongly } \\
\text { Agree }\end{array}$ & Highly Acceptable \\
\hline \multicolumn{3}{|c|}{ Grand Mean: } & \multicolumn{3}{|c|}{4.915} & \\
\hline \multicolumn{3}{|c|}{ Verbal Interpretation: } & \multicolumn{3}{|c|}{ Highly Acceptable } & \\
\hline $\begin{array}{l}\text { Legend: } \\
\text { Scale } \\
4.20-5.00 \\
3.40-4.19 \\
2.60-3.39 \\
1.80-2.59 \\
1.00-1.79\end{array}$ & & $\begin{array}{l}\text { Remarks } \\
\text { Strongly Agree } \\
\text { Agree } \\
\text { Moderately Agree } \\
\text { Disagree } \\
\text { Strongly Disagree }\end{array}$ & $\begin{array}{l}\boldsymbol{V e} \\
\mathrm{Hi} \\
\mathrm{Ac} \\
\mathrm{Mc} \\
\mathrm{Sli} \\
\mathrm{No}\end{array}$ & $\begin{array}{l}\text { al Interpre } \\
\text { y Acceptal } \\
\text { ptable } \\
\text { rately Acc } \\
\text { tly Accepta } \\
\text { tcceptable }\end{array}$ & able & \\
\hline
\end{tabular}

The table shows that among its characteristics, the item that ranked first is usability with $(\mathrm{WM}=4.941)$, as the respondents noticed that the system is appropriate to help students to in acquiring of skills needed in passing the licensure examination for teachers. And, the item that ranked last is accessibility with (WM=4.897). Its overall assessment in terms of its characteristics received an overall rating of $(\mathrm{WM}=4.915)$ with a verbal interpretation of "Highly Acceptable."

Table 3 reflects the significant difference on the level of assessment of teachers and students on the developed Automated Licensure Examination Reviewer for Teachers (A.L.E.R.T).

Table 3. Significant Difference on the Student's and Teacher's Level of Assessment on the Component and Characteristics of Automated Licensure Examination Reviewer for Teachers (A.L.E.R.T.)

\begin{tabular}{|c|c|c|c|c|c|c|c|}
\hline \multirow[t]{2}{*}{ Assessment } & \multicolumn{2}{|c|}{$\begin{array}{c}\text { Estimation for } \\
\text { Paired } \\
\text { Difference }\end{array}$} & \multicolumn{2}{|c|}{$\begin{array}{c}95 \% \mathrm{Cl} \text { for } \boldsymbol{\mu} \\
\text { differences }\end{array}$} & \multirow[t]{2}{*}{$\begin{array}{c}\text { T- } \\
\text { Value }\end{array}$} & \multirow[t]{2}{*}{$\begin{array}{c}\text { P- } \\
\text { Value }\end{array}$} & \multirow[t]{2}{*}{$\begin{array}{c}\text { Verbal } \\
\text { Interpretation }\end{array}$} \\
\hline & Mean & SDev & LB & HB & & & \\
\hline $\begin{array}{l}\text { Component and } \\
\text { Characteristic of } \\
\text { A.L.E.R.T. System }\end{array}$ & 1.5391 & 0.2814 & 0.9802 & 2.0979 & 5.4690 & 0.0000 & Significant \\
\hline
\end{tabular}


Table 3 shows the difference on the Student's and Teacher's Level of Assessment on its Component and Characteristics. The data were statistically treated using the Normal probability known Paired T-test. Its variable characteristics paired to its components.

The following estimation for paired difference, $95 \% \mathrm{CI}$, T-value and P-value: The assessment of its components and characteristics that has a mean value of (1.5391) with standard deviation (0.2814) for the estimation for paired difference which is rejected since the $\mu$ (difference of assessment) is not equal to 0 with T-value of 5.4690 and P-value 0.0000 with verbal interpretation of "Significant."

It is clear that the assessment on the component, such as content, format, graphics and objectives and functional characteristics as to its accessibility, consistency, suitability and usability received a remarkable rating hence, interpreted as "Highly Acceptable" as evaluated by both teachers and students. Furthermore, on the basis of evidence, technology promotes a substantive concept and style of learning to diversified students who are preparing for the licensure examination for teachers, thus acquire necessary skills and techniques to ensure chances in passing the said examination.

\section{CONCLUSIONS AND RECOMMENDATIONS}

From the data collected and interpreted, it was found out that the developed Automated Licensure Examination Reviewer for Teachers (A.L.E.R.T.) is rated as "Highly Acceptable" in terms of its components such as its content, format, graphics and objectives. In terms of the system's functional characteristics, it was also rated as "Highly Acceptable", hence, the system was evidently found accessible, consistent, suitable and usable thus may serve as an alternative review platform in preparation in taking up the licensure examination for teachers. The overall mean of significance proved that there is a significant difference on its level of assessment in terms of its components and characteristics therefore the null hypothesis is rejected.

\subsection{Recommendations}

Based on the findings and conclusions, the following recommendations were suggested by the researcher: (1) Full implementation of its usage for the students from first year to fourth year of the College of Teacher Education is encouraged to support the preparation of students in taking up the licensure examination for teachers and for the improvement of LET performance and to evaluate the effectiveness of the system; (2) The system is as good as its content, which means all professors and instructors of general and professional education subjects are highly encouraged to contribute questions to be added to its question databank; (3) Periodic update of the question's databank is highly encouraged to ensure relevance of the review materials; (4) Establish a centralized question databank for record keeping of questions, if possible, questions coming from the past licensure examination given by the Professional Regulation Commission.

\section{ACKNOWLEDGMENTS}

The author wishes to extend appreciation to the participants of the study. 


\section{REFERENCES}

Books

Himmel, J. (2012). "Language Objectives: The Key to Effective Content Area Instruction for English Learners". Colorado, USA.

Hougan, E. (2015). Five Ways to Teach with Learning Objectives. New Teaching Community. USA.

Richardson, et. al. (2009). Reading to Learning in the Content Areas Wadswort. Cengage Learning Publishing, USA.

Published/Unpublished Materials

Aragon, C. (2017). Supplementary Material in Enhancing Reading Comprehension of Grade 7 Students. Unpublished Master's Thesis, Laguna State Polytechnic University, Los Baños Campus, Loas Baños, Laguna.

Bagasin, G. (2018). Development of Peer Assisted Tutoring Module in English for Grade 8 Students. Unpublished Thesis, PSA, Metro Manila, Philippines.

Cabantog, J. (2019). Web-based Licensure Examination for Teachers (LET) Reviewer for Technology and Livelihood Education (TLE) Focused in Home Economics. Unpublished Master's Thesis, Laguna State Polytechnic University Sta. Cruz Campus, Sta. Cruz, Laguna.

Cabantog, M. L. (2016). Development and Validation of Module in Geometry. Unpublished Master's Thesis, Laguna State Polytechnic University Sta. Cruz Campus, Sta. Cruz, Laguna.

Esmeria, G. and Seva, R. (2017). Web Utility: A Literary Review. DLSU Research Congress.

Hougan, E. (2015). Five Ways to Teach with Learning Objectives. New Teaching Community. USA.

Kamalrudin, M., Grundy J. and Hosking J. (2012). "Supporting Requirements Modelling in the Malay Language using Essential Use Cases." in Proc. IEEE Symposium on Visual Languages and Human-Centric Computing. Innsbruk, Austria: IEEE.

Kuh, G. D. (2009). The National Survey of Student Engagement: Conceptual and Empirical Foundations. New Directions for Institutional Research, 141,5-20.

Madan, A. and Dubey, S. K. (2012). Usability Evaluation Methods: A Literature Review. vol. 4, no. 02, pp. 590-599.

Miguel J.P., Mauricio D., Rodríguez G. (2014). A Review of Software Quality Models for the Evaluation of Software Products. 5(6):3153.

Moumane K., Idri A., Abran A. (2016). Usability Evaluation of Mobile Applications using ISO 9241 and ISO 25062 Standards. Springerplus.

Rodríguez, M., and M. Piattini. (2012). Systematic review of software product certification: In Proceedings of the 7th Iberian Conference on Information Systems and Technologies (CISTI 2012), Madrid, Spain, 631-636.

W. ISO, "9241-11. (1998). Ergonomic Requirements for Office Work with Visual Display Terminals (VDTs). The International Organization For Standardization, vol. 45.

Journals

Bahill, A. T. and Henderson, S. J. (2005). Requirements Development, Verification, and Validation Exhibited in Famous Failures. Syst. Eng., vol. 8, pp. 1-14.

Charlie, S. (2012). Article Writing Format, Journal on Publishing. England. Cambridge University Press, vol. 7 , Issue 2.

Dagdag, D., Sarmiento, C. Ibale, J. (2017). Examining the Factors of Licensure Examination for Teachers Performance for Program Strategy Enhancement. Asia Pacific Journal of Multidisciplinary Research, 5(4), 34-39.

Harrison R., Flood D., and Duce D. (2013). Usability of Mobile Applications: Literature Review and Rationale for a New Usability Model. Journal of Interaction Science, vol. 1, pp. 1-16.

Kamalrudin, M. and Sidek, S. (2015). A Review on Software Requirements Validation and Consistency Management. International Journal of Software Engineering and its Applications.

Krasna, M. (2011). Aesthetics and Creativity in E-Learning Material. University of Slovenia, Vol. 12, No. 1-2.

Madan, A. et al. (2012). Usability Evaluation Methods: A Literature Review. International Journal of Engineering Science and Technology (IJEST), 4(2), pp. 590-599.

Richardson, W. (2009, 1 September 1). Personalized online learning. District Administration. Retrieved October 1, 2011, from www.districtadministration.com/ article/personalized-online-learning

Rodriquez, M. et. al. (2016). Evaluation of Software Product Functional Suitability: A Case Study. Software Quality Management, vol. 18 , pp. $18-29$

Visco, D. (2015). Predictors of performance in the licensure examination for teachers of the graduates of higher education institutions in Abra. International Journal of Management Research and Business Strategy, 4(1), 181-191.

Zowghi, D. and Gervasi, V. (2003). On the Interplay Between Consistency, Completeness, and Correctness in Requirements Evolution. Information and Software Technology, vol. 45, pp. 993-1009. 
Internet Sources

Coates, H. (2008). Attracting, engaging and retaining: New conversations about learning. Camberwell: Australian Council for Educational Research Retrieved from http://research.acer.edu.au/cgi/view content.cgi? article=1015\&context=ausse.

Gandhi, P., Khanna, S., \& Ramaswamy, S. (2016). Which industries are the most digital (and why?). Retrieved from https://hbr.org/2016/04/a-chart-that-shows-which-industries-are-the-most-digital-and-why.

Gupta, S. (2017). 9 Benefits Of eLearning For Students. Retrieved from https://elearningindustry.com/9-benefits-of-elearning-forstudents.

Mcdonald-Ross, M. (2016). Research in Graphic Communication: Graphics in Texts: How Numbers are Shown. IET Manograph No. 7 Retrieved from http://hollis.harvard.edu

Nielsen J. (2012). Usability 101: Introduction to Usability. Retrieved from https://www.nngroup.com/articles/usability-101-introductionto-usability

Pappas, C. (2015). Writing Learning Objectives for e-Learning. Retrieved from https://elearningindustry.com/writing-learningobjectives-for- elearning-what-elearning-professionals-should-know.

Poushter, J. (2016). Smartphone ownership and internet usage continues to climb in emerging economies. Washington, D. C.: Pew Research Center Retrieved from http://www.pewglobal.org/2016/02/22/ smartphone-ownership-andinternet-usage-continues-toclimb-in-emerging-economies/.

SETDA and EducationCounsel LLC (2014). The Accessibility of Learning Content for all Students, Including Students With Disabilities, Must Be Addressed In The Shift To Digital Instructional Materials. Retrieved from https://www.setda.org/wpcontent/uploads/2014/03/SETDA_PolicyBrief_Accessibility_FNL.5.29.pdf

Trowler, V. (2010). Student Engagement Literature Review. Lancaster University Retrieved from http://www. lancaster.ac.uk/staff/trawler/StudentEngagementLiteratureReview.pdf.

Willows, D. (2013). The Psychology of Illustration Volume 1 Basic Research Editor. Retrieved from http://www.springer.com/gp/book/978146129 1107.

Christian P. San Luis is a graduate of MA in Education major in Educational Management (2020) and currently taking up Doctor of Philosophy major in Educational Leadership Management at Laguna State Polytechnic University. He finished his baccalaureate degree, BSEd major in Computer Education at Don Bosco College, Canlubang Laguna in 2000. At present, he teaches computer programming courses to undergraduate students of Laguna State Polytechnic University Sta. Cruz Campus. 